\title{
THE ROLE OF AIRBORNE EM METHODS IN ENVIRONMENTAL APPLICATIONS
}

${ }^{1}$ British Geological Survey (BGS), Keyworth, Nottingham, NG12 5GG, UK (D.Beamish@bgs.ac.uk)

\begin{abstract}
During the past fifteen years environmental scientists have applied airborne geophysical techniques increasingly to the mapping and monitoring of potential environmental hazards such as leakage from landfill sites, the spread of polluted groundwaters and the distribution of possibly harmful natural and artificial radionuclides. Explorationists first applied these techniques more than 60 years ago, initially for metallic mineral exploration in Shield areas. In later years the sensors and techniques were improved and also applied to hydrocarbon exploration and geological and structural mapping. The rapid emergence of airborne techniques in environmental studies can be attributed to ease of access to 'difficult' sites, comprehensive data coverage and remote, rapid and non-invasive acquisition of data which in turn informs highly focussed confirmatory ground follow up activities. Airborne multi-sensor platforms now typically include magnetic (gradiometer), radiometric and electromagnetic measurements. Due to time restrictions, the talk will focus on the increasing role of Airborne EM (AEM) methods for environmental purposes. Although the issue of time/frequency domain AEM systems can be debated, a requirement for multi-sensor measurements places the focus on modern frequency domain measurements.
\end{abstract}

The environmental business and research sector is already large and it is growing in value, scale and complexity. Ground-based geophysics, particularly non-seismic methods, already has an established presence. From the perspective of a geological survey, it is possible to consider 'growing' AEM survey data from the local, to the regional and thence to the national scale. The drivers (potential users) of airborne information become an important component when developing these types of programme. Within Europe, key words include sustainability and climate change. Within this framework, airborne surveys offer both baseline and monitoring capabilities. The talk considers both helicopter and fixed-wing AEM survey techniques and data; what they can do and what they can deliver. Example studies, from programmes underway in Europe, with particular reference to the UK, are provided. 